\title{
Global Financial Model for Responsible Research and Development of the Fast Growing Nanotechnology Business
}

\section{Farid Menaa*}

R\&D Executive Director, Department of Nanomedicine and Nanotechnology, Fluorotronics, Inc and Co, USA

Nanotechnology, called sometimes "molecular manufacturing", originates from the Greek word meaning "dwarf”. Nanotechnology is a fast growing branch of engineering that deals with dimensions and tolerances of less than 100 nanometers (i.e. manipulation of individual atoms and molecules). A nanometer is one billionth (10-9) of a meter, which is as tiny as a virus or as a one hundred thousandth of the width of a hair!

Nanotechnology represents an exciting multi- and interdisciplinary area of scientific and business development. It can also be defined as an "emerging" technology in the sense that it: (i) arises from new knowledge, or the innovative application of existing knowledge; (ii) leads to the rapid development of new capabilities; (iii) is projected to have significant systemic and long-lasting economic, social and political impacts; (iv) creates new opportunities and challenges to addressing global issues; (v) has the potential to disrupt or create entire industries. Thereby, nanotechnology promises "more for less", offering opportunities in creating alternative/disruptive solutions (i.e. new functions and features) to several long-standing environmental and human problems (i.e. diseases, eco-toxicity, non-sustainable energy). Nanotechnology is currently being applied to many areas of research and development ranging from medicine (e.g. cancer theranostics, regenerative medicine) to electronics (e.g. biosensors) [1-3]

In terms of socio-politico-economics, nanotechnology has a great overall impact and represents a global interest. Indeed, it offers ways to create more, cheaper, smaller, lighter, faster, sustainable and innovative devices that can use less raw materials and energy. Nevertheless, in some segments (e.g. medicine, food and cosmetics), nano-safety and "nano-ethical" concerns still require to be better addressed.

In terms of finances, many countries have developed nanotechnology programs since the US National Nanotechnology Initiative (NNI) was announced in 2000 [4-6]. Importantly, this disruptive technology is attracting more public funding than any other area of technology, estimated in US \$ billion worldwide. According to the World Economic Forum's Annual Global Competitiveness Report 2011 [7], the world's governments increasingly (about 20\%) spent US $\$$ billions per year (about 10) on nanotechnology research and development [8]. By 2014, it is expected that the total government funding for nanotechnology research worldwide will reach US \$100 billion (Figure 1), and by 2015, it is estimated that nearly US $\$ 1$ trillion dollars will be invested into nanotechnology programs when corporate research and various other forms of private funding are taken into account, which are thought to contribute more than public funding alone [5, 7-8]. In absolute terms, US still comprehensively outspends other countries (e.g. China, Russia, Germany or Japan) (Figure 1) [8]. A fast trend is emerging that is related to fast growth rates of Asian nanotechnology research spending (i.e. purchasing power parity PPP) (Figure 2) [8].

Since the amount of funding - whether in raw \$ or PPP corrected -, fails to tell the whole story (i.e. whether the translated conducted research will have an - beneficial - impact on the economy), an emerging technology exploitation factor (ETEF) has been then

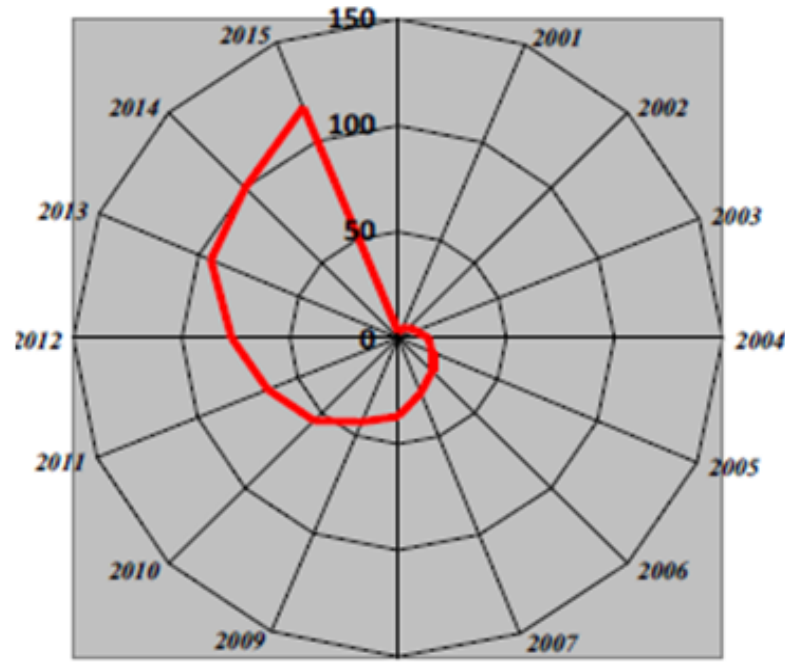

Figure 1: Trend of Total Global Nanotechnology Funding (US \$ Billion)

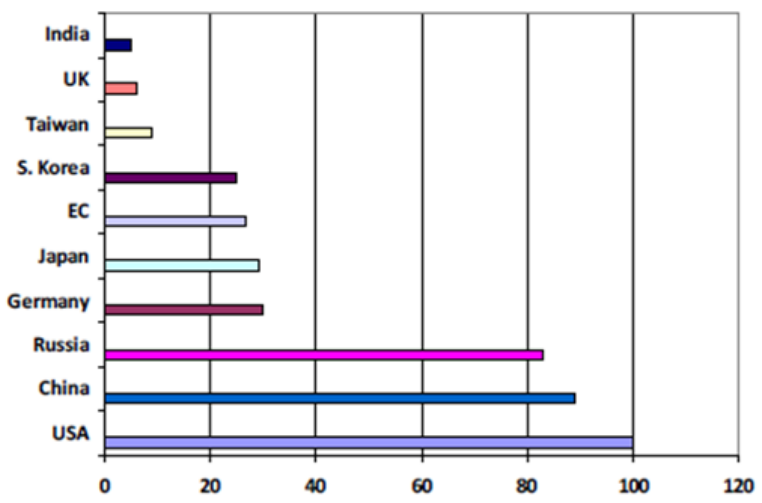

Figure 2: Nanotechnology Impact Factor (Purchasing Power Parity - PPP corrected)

*Corresponding authors: Dr. Farid Menaa, R\&D Executive Director, Department of Nanomedicine and Nanotechnology, Fluorotronics, Inc.\& Co, San Diego, California, USA, Tel: +1-858-274-272; E-mail: dr.fmenaa@gmail.com

Received December 26, 2013; Accepted December 27, 2013; Published January 2, 2014

Citation: Menaa F (2014) Global Financial Model for Responsible Research and Development of the Fast Growing Nanotechnology Business. J Bus Fin Aff 3:e139 doi:10.4172/2167-0234.1000e139

Copyright: @ 2014 Menaa F. This is an open-access article distributed under the terms of the Creative Commons Attribution License, which permits unrestricted use, distribution, and reproduction in any medium, provided the original author and source are credited. 


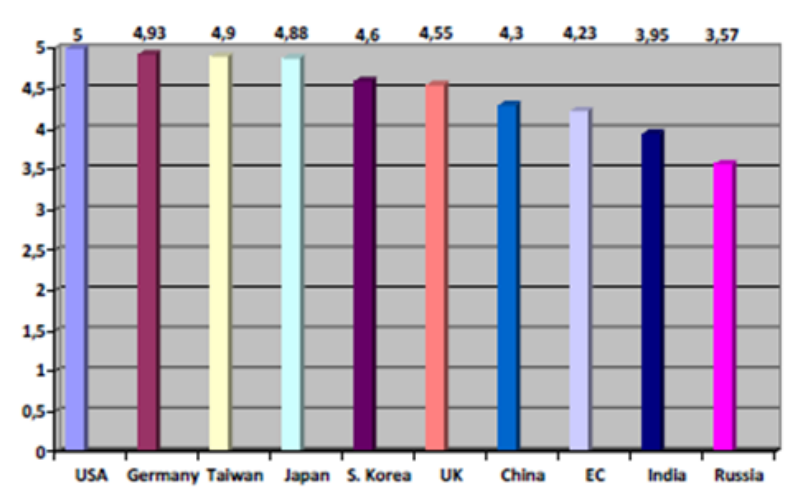

Figure 3: Emerging Technology Exploitation Factor (ETEF) Worldwide

produced [8] by combining macroeconomic data such as the overall global competitiveness [7], quality of scientific institutions, capacity for innovation and levels of company spending in R\&D with a number of relevant factors (Figure 3) [8].

Global investments, return into investments (ROI) in nanotechnology and impacts socio-politico-economics worldwide, taking into account public and private funding, seem to be poised to substantially grow in the coming years...

\section{References}

1. Menaa B (2011) The Importance of Nanotechnology in Biomedical Sciences. J Biotechnol Biomaterial1:e105.

2. Menaa F, Menaa B (2012) Development of Mitotane Lipid Nanocarriers and Enantiomers: Two-in-One Solution to Efficiently Treat Adreno-Cortical Carcinoma. Curr Med Chem19:5854-5862.

3. Menaa F (2013) Functional Graphene-Based Nanobioimaging Platforms: New Powered Real-Time Interfaces. J Mol Imaging Dynam2:e103.

4. About the NNI (2000) National Nanotechnology Initiative, Nano.gov.

5. Roco MC (2007) National Nanotechnology Initiative - Past, Present, Future Taylor and Francis, (2ndedn), Handbook on Nanoscience, Engineering and Technology.

6. Sargent Jr. JF (2013) The National Nanotechnology Initiative: Overview, Reauthorization, and Appropriations Issues. Congressional Research Service.

7. Schwab K(2010) The Global Competitiveness Report 2010-2011. World Economic Forum.

8. Harper T (2011) Global Funding of Nanotechnologies \& Its Impact. Cientifica. 